\title{
Understanding the Thickening Process
}

\author{
B.J. Gladman, S.P. Usher, P.J. Scales Dept. of Chemical and Biomolecular Engineering, The University of \\ Melbourne, Australia
}

\section{INTRODUCTION}

The thickening process is the primary method of producing high solids slurries for the minerals industry. Thickener outputs can accommodate a range of tailings disposal options from low yield stress, easily pumped suspensions for disposal in conventional 'wet' tailings dams to more concentrated slurries for delivery to 'dry disposal' and backfill applications. The thickening process, although operated successfully in a large range of sites around the world, is poorly understood and predictive design of thickening devices is still empirical. Although predictive models of thickening do exist, the correlation to reality is often poor and there is a desperate need to bring the two together to make rational improvements to thickener design and operation. Therefore, whilst some would dismiss the models as being unacceptable for predictive design, they are very useful in formulating expected operational trends and providing an understanding of the directions one should take in improving operational performance. The aim of this article is to bring together model, laboratory and in-field results to elucidate the state of the art in understanding thickener operation from first principles.

\section{PRINCIPLES}

In simple terms, dewatering in a thickener involves gravity acting on the density difference between the solid particles and the carrier liquid (usually water), enabling the solid particles to settle. As the solids concentration of the slurry increases, the settling rate progressively slows and above a critical solids concentration known as the gel point, $\phi_{g}$, the slurry exhibits a network structure and forms a bed at the base of the vessel.

Historically, improvements in the performance of industrial thickeners have been based on selecting conditions that produce desired properties in settling test behaviour, such as the free settling rate, final sediment solids concentration, viscosity or shear yield stress. These tests have proved useful in optimising thickener performance and are loosely based on suspension material properties, but they do not enable quantitative prediction of thickener performance. Such prediction requires a more thorough understanding of the physical suspension properties that determine the rate and extent of dewatering. This is not to suggest that the current tests should be abandoned, just that they should be enhanced where or whenever practical.

Compressive yield stress and permeability have been established as fundamental physical properties that determine suspension dewaterability (Buscall and White, 1987). To determine these properties across the solids concentration regime typical of thickener operation (very dilute feed to thickened underflow), 
experimental techniques have been developed to allow rapid and comprehensive dewaterability characterisation. These tests include batch settling, gravity permeation, centrifugation and pressure filtration (de Kretser et al., 2001; Green, 1997; Green et al., 1998; Lester et al., 2005; Usher et al., 2001). In the case of batch settling tests (Lester et al., 2005), the testing is straight forward and reliable and can be performed both on-site and in the laboratory. The subsequent extraction of the fundamental physical properties is not trivial but has been packaged into a software tool that is reasonably quick to use.

To complement the measurement of the material properties of the flocculated suspensions to be dewatered, numerous authors have presented fundamentally based equations and computational algorithms for predicting transient thickener performance (Bürger et al., 2000; Lester, 2003; Martin, 2004) and steady state thickener performance (Garrido et al., 2003; Green, 1997; Landman et al., 1988; Landman et al., 1994; Usher and Scales, 2005) from material properties algebraically related to the compressive yield stress and permeability. The outputs of these algorithms enable understanding of how process variations can affect dewatering performance. The key disadvantage of the transient algorithms is that they require large amounts of computation time to model a wide range of conditions. Use of the quicker, simpler steady state thickening algorithms enables a wider range of conditions to be modelled.

As an example of the outputs of these models, the case of a suspension of flocculated red mud from the washer train of an Australian refinery is shown in Figure 1. In this case, the algorithm derived by Usher (Usher and Scales, 2005) has been applied to predict the performance. To achieve this end, experimental permeability and compressibility data was obtained on-site using a combination of batch settling tests and filtration. The data from these tests was curve fitted with an appropriate algorithm such that the noncontinuous experimental data could be input to the model and a broad range of scenarios investigated. Other inputs to the model included feed solids, solution viscosity, solids density (to allow conversion from weight to volume percent solids) and thickener geometry. A range of throughput and bed height scenarios are presented in Figure 1.

At high throughput, usually given as a solids flux (tonnes of solids $/ \mathrm{hr} / \mathrm{m}^{2}$ ), the model predicts that the thickener will give underflow solids that are independent of the operational bed height. As solids flux decreases, the underflow will reach the gel point of the suspension and the dependence on the operational bed height will become more important. The underflow will also exhibit a shear yield stress above the gel point and operational points based on suspension yield stress or slump height could be incorporated into the same figure. This would obviously require a separate determination of the shear yield stress or slump height as a function of solids concentration. The solids concentration in Figure 1 is given as a volume fraction of solids although it is relatively easy to provide a conversion to weight fraction of solids if the solids density is known.

A closer look at the model data indicates that for underflow solids up to and just in excess of the gel point, the operation of the thickener is limited by permeability alone in that any enhancement in the permeability of 
the settling flocs will increase the underflow solids. The effect of bed height will be important for solids concentrations above the gel point but the operation will still be limited by permeability unless the solids flux is very low. A survey of thickener operations shows that since the ability to rake and pump the underflow solids is limiting, the majority of operational thickeners will be permeability limited and provided they are run at a bed height in excess of 2-3 meters, operational changes that enhance the settling rate of the flocculated solids or the permeability of the solids bed will be beneficial to improving either of underflow solids or solids throughput.

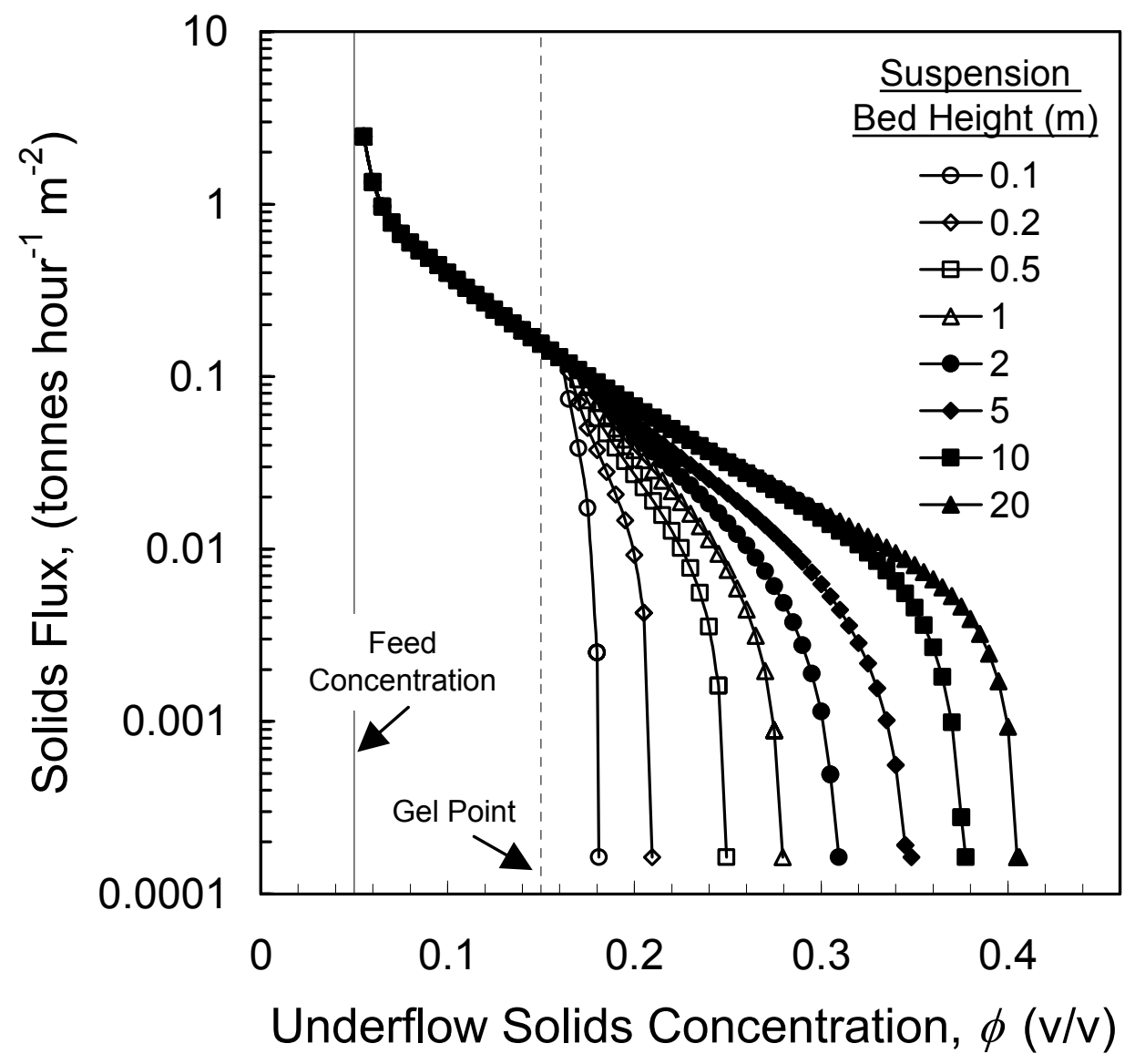

Figure 1 Typical steady state converging base thickener model prediction of the solids flux as a function of underflow solids volume fraction for a range of suspension bed heights for an Australian alumina plant (red mud) slurry (Usher, 2002)

\section{MODEL PREDICTIONS AND INDUSTRIAL REALITY}

\subsection{Modelling}

The model predictions presented in Figure 1 allow comparisons of process performance with model predictions for thickening operations. Quite obviously, every operational scenario will produce a different 
model output. Perhaps more importantly, changes in floc formation conditions as either a change in the solids concentration of floc formation or a change in the dose or type of flocculant will produce a different model output. This is because the material properties, measured as either the compressibility of permeability of the flocculated suspension have been shown to be sensitive to the changes in floc dose and conditions.

The validation exercise also gives an indication of the level to which factors other than those observed in simple settling tests influence the rate and extent of dewatering. The functional inputs to the model only incorporate settling, hindered settling and network compressibility in the absence of shear. The role of raking and other shear processes on enhancing dewatering are not included. Qualitatively and anecdotally, these processes will be important. Observations for simple batch settling tests show that in the presence of raking or shear, enhancements in settling rate are common. Figure 2 is an example of laboratory data from a simple batch settling test in the presence of raking. A clear improvement in settling is observed that more detailed analysis shows is due to an enhancement of the settling in both the hindered settling regime and in the escape of liquid from the network bed of particles at the bottom of the cylinder, as also occurs in a thickener.

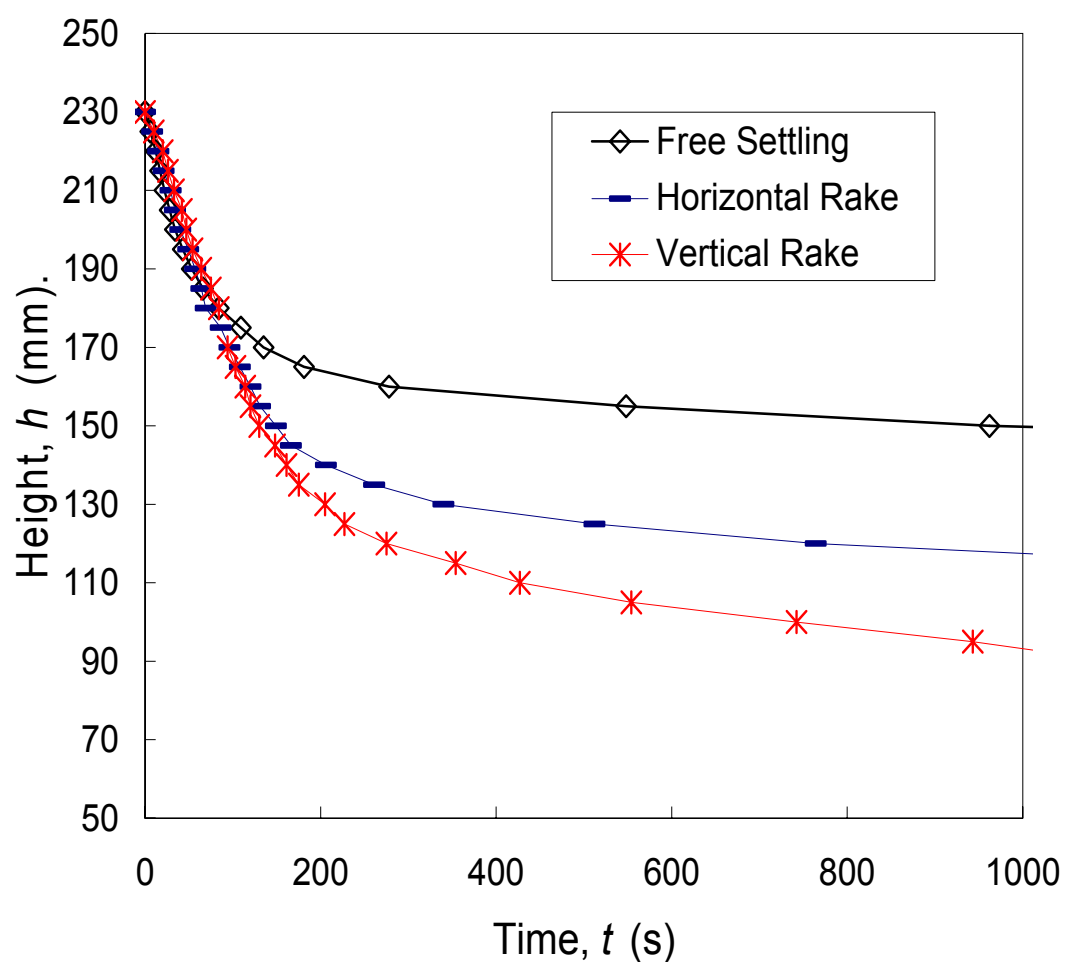

Figure 2 Transient batch settling test data for a normal settling test (free settling), settling with a horizontal rake and settling with a vertical rake

An example of the comparison of the prediction of the thickener model against an operational scenario for red mud thickening in the alumina industry is shown in Figure 3. The modelling data is for two bed heights, namely 2 and 5 meters. The input data for the model was measured on-site using samples taken from the underflow and re-flocculated using the same dose of polymer as in the actual device. 


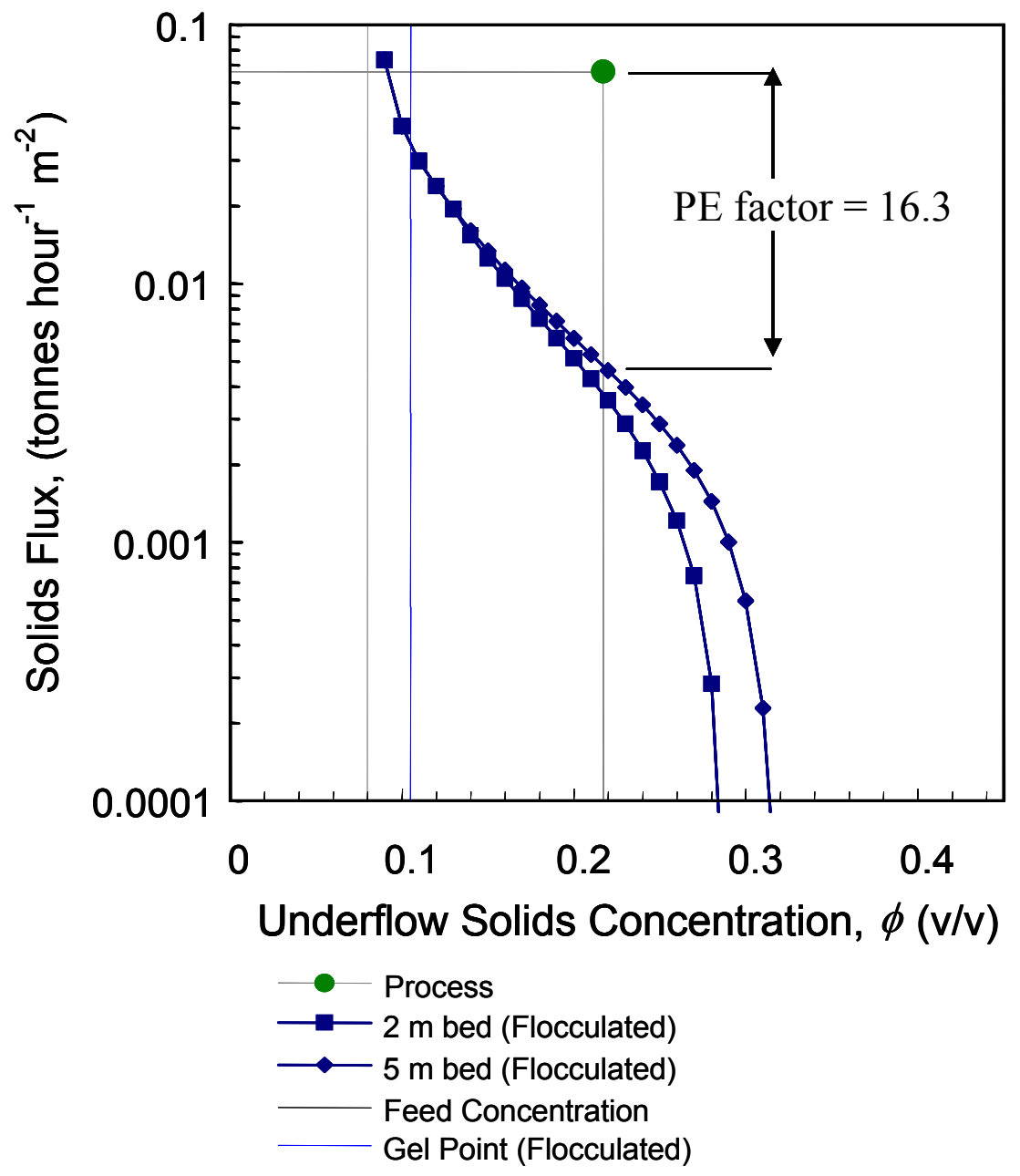

Figure 3 Red mud thickener performance and model prediction of the solids flux versus observed underflow solids volume fraction. The difference between predicted and actual performance is indicated as a performance enhancement (PE) factor (Usher, 2002)

Whilst there is a possibility that the material was not flocculated in an identical manner, the difference in predicted versus actual performance is substantial. In terms of the solids flux through the thickener, the difference was a factor of 16.5. This has been labelled as a performance enhancement (PE) factor in Figure 3. The model predicts that at the operational flux, the red mud would achieve an underflow solids concentration less than the gel point. The reality is an underflow solids concentration in excess of the gel point and indeed, in this case, the material had a yield stress approaching $100 \mathrm{~Pa}$.

\section{$3.2 \quad$ Operational outcomes}

Analysis of a range of industrial thickeners from the processing of gold ores, red mud, coal tailings, potable water sludge and clay suspensions shows that current mathematical models generally underestimate thickener throughput at a given underflow solids concentration. Performance enhancement factors of up to 100 have been observed for selected materials in high rate thickeners. Whilst these performance 
enhancements are quite variable, more typical figures of between a factor of 5 and 20 have been observed for conventional thickening operations. Some other results for a range of thickeners are shown in Figure 4.

The operational outcomes compared to the model predictions should and do give the modelling community cause to question the physical description of the sedimentation process that is incorporated into the models. As stated earlier, this is simplistic in that it assumes that a floc settles, becomes hindered in its settling and then forms a bed. Compression in the bed due to particle self weight causes further consolidation. This is more sophisticated than a Kynch style flux approach (Kynch, 1952) and one could reasonably argue that in terms of just sedimentation and consolidation, the approach cannot be flawed since it is able to describe batch settling accurately and consistently. Indeed, the experimental parameter estimation procedures typically use batch settling as a basic input.

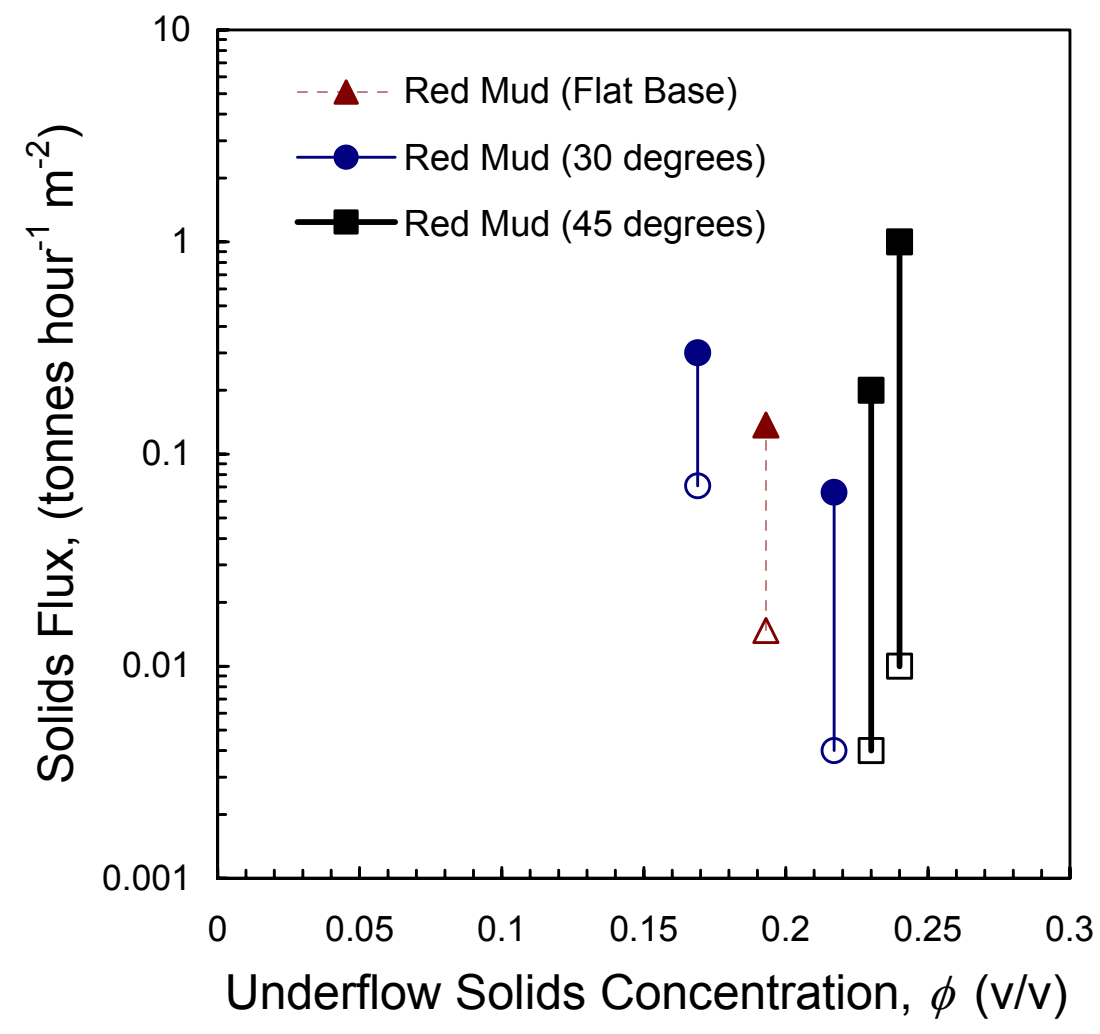

Figure 4 Industrial thickener performance and model prediction of the solids flux versus observed underflow solids volume fraction. The data is for thickeners with shapes ranging from a flat base to a deep cone thickener with a cone angle of $45^{\circ}$ (data obtained from Usher, 2002)

It has long been believed that the difference between the model predictions and operational reality is the role of raking of the bed to aid consolidation and channelling in the thickener to aid the release of water. Whilst this is obviously important, an interesting observation from Figure 3 is that the model predicts an underflow solids of less than the gel point. This observation and subsequent modelling of the data in Figure 2 for the 
case of raked solids in a batch settling test, shows that whilst raking of the bed enhances settling and improves both the rate and extent of dewatering, this alone is not enough to account for the observed performance enhancement factors.

Recent work (Gladman et al., 2005) shows that it is the role of very low shear processes in both the settling and hindered settling regions of the thickener as well as in the bed of the thickener that is critical to performance enhancement. These low shear processes result in a slow change in floc structure that is not able to be quantified in a classical batch settling experiment because the time domain in free and hindered settling in most batch settling experiments is short (of order seconds). This is in contrast to steady state thickening where this time domain may extend for hours. This leads to the postulate that the role of the bed height in enhancing compression in a thickener is probably outweighed by the role of increasing residence time for floc restructuring in shear. The role of rakes and pickets in allowing the restructuring to happen on a far shorter time scale is also noted although excess shear has been shown to be highly detrimental to the enhancement (Gladman et al., 2005). Modelling of thickener performance with shear of the free settling, hindered settling and bed regions, although the result of rudimentary experiments, shows that this factor is able to account for performance enhancements of up to 20. It is likely that this will be extended for flocs with a different structure. The encouraging sign is that the model is now able to predict a wide range of operational scenarios.

\section{CONCLUSIONS}

The discussion in this article has focussed on the measurement of the parameters important to thickening and the modelling of operational thickeners using these parameter inputs. This has produced an enhanced level of understanding of the factors that are important to thickener operation and provided a quantitative prediction of thickener performance for the first time. The lessons learnt through this exercise are that an increase in thickener solids flux or underflow solids are manifest in improvements in settling and bed permeability behaviour. It is common to approach such an improvement through increased floc dosage which in turn manifests as a faster free settling rate in the thickener. The modelling information shows that this is not sufficient and it is the ability of the floc to restructure in shear that is a more critical operational parameter. It is expected that this conclusion will provide a better understanding of the choice of flocculants in thickening and equally, the choice of raking elements and shear rates employed.

\section{ACKNOWLEDGEMENT}

The financial support of the Particulate Fluids Processing Centre, a special research centre of the Australian Research Council and AMIRA, through projects P527 and P266D is gratefully acknowledged. One of us, BJ Gladman, acknowledges receipt of an Australian Postgraduate Award (Industry) from the Australian Government. 


\section{REFERENCES}

Bürger, R., Evje, S., Hvistendahl Karlsen, K. and Lie, K.A. (2000) Numerical methods for the simulation of the settling of flocculated suspensions. Chemical Engineering Journal 80, pp. 91-104.

Buscall, R. and White, L.R. (1987) The consolidation of concentrated suspensions J. Chem. Soc. Faraday Trans. I 83, pp. 873-891.

de Kretser, R.G., Usher, S.P., Scales, P.J., Boger, D.V. and Landman, K.A. (2001) Rapid measurement of dewatering design and optimization parameters. AIChEJ 47, pp. 1758-1769.

Garrido, P., Burgos, R., Concha, F. and Bürger, R. (2003) Software for the design and simulation of gravity thickeners Minerals Engineering 16, pp. 85-92.

Gladman, B., de Kretser, R.G., Rudman, M. and Scales, P.J. (2005) Effect of shear on particulate suspension dewatering Transactions Institute of Chemical Engineers 83, pp. 1-4.

Green, M.D. (1997) Characterisation of suspensions in settling and compression. Department of Chemical Engineering, The University of Melbourne, pp. 246.

Green, M.D., Landman, K.A., de Kretser, R.G. and Boger, D.V. (1998) Pressure filtration technique for complete characterisation of consolidating suspensions Ind. Eng. Chem. Res. 37, 10, pp. 4152-4156.

Kynch, G.J. (1952) A theory of sedimentation Transactions of the Faraday Society 48, pp. 166-176.

Landman, K.A., White, L.R. and Buscall, R. (1988) The continuous flow gravity thickener: Steady state behaviour AIChEJ 34 pp. 239-252.

Landman, K.A., White, L.R. and Eberl, M. (1994) Solid/liquid separation of flocculated suspensions. Advances in Colloid and Interface Science 51, pp. 175-246.

Lester, D.R. (2003) Colloidal suspension dewatering analysis. PhD Thesis in Department of Chemical and Biomolecular Engineering, University of Melbourne, Australia.

Lester, D.R., Usher, S.P. and Scales, P.J. (2005) Estimation of the hindered settling function R(f) from batch settling tests AIChEJ 51, 4, pp. 1158-1168.

Martin, A.D. (2004) Optimisation of clarifier-thickeners processing stable suspensions for turn-up/turn-down. Water Research 38, pp. 1568-1578.

Usher, S.P., de Kretser, R.G. and Scales, P.J. (2001) Validation of a new filtration technique for dewaterability characterization. AIChEJ 47, pp. 1561-1570.

Usher, S.P. and Scales, P.J. (2005) Steady state thickener modelling from the compressive yield stress and hindered settling function. Chemical Engineering Journal 111, pp. 253-261.

Usher, S.P. (2002) Suspension dewatering: characterisation and optimisation PhD Thesis in Department of Chemical Engineering, The University of Melbourne, Australia. 